Received: November 21, 2017

\title{
Study on the Application of Pronunciation Training in Vocal Music Teaching in Colleges and Universities
}

\author{
Yang Zhang ${ }^{1}$ \\ Jie Xing ${ }^{2}$ \\ Hebei Agricultural University \\ Hebei Agricultural University
}

\begin{abstract}
Many researches show that college students are not keen in learning vocal music, and their satisfaction with vocal music teaching is low. How to improve the teaching effect of vocal music teaching in colleges and universities has become a popular concern. Under this background, this study introduces pronunciation training into the vocal music teaching in colleges and universities, and probes into the promoting effect of pronunciation training on the teaching effect of vocal music in colleges and universities. The results show that pronunciation training can increase students' basic knowledge of music theory, enhance their basic understanding of vocal music, improve their interest in learning vocal music, and finally improve the practical effect of vocal music teaching in colleges and universities. This study is of practical guiding significance to the development of vocal music teaching in colleges and universities, especially non-art colleges and universities.
\end{abstract}

\section{Keywords}

Pronunciation Training • Vocal Music Education • Colleges and Universities

\footnotetext{
${ }^{1}$ Correspondence to: Yang Zhang (MA), Hebei Agricultural University, Baoding 071001. Email: yangaijie851128@126.com

${ }^{2}$ Hebei Agricultural University, Baoding 071001. Email: 420349976@qq.com
} 
Colleges and universities are the base of training high-level talents. At present, the demand for talents has changed from simply paying attention to skills to all-round development. In this context, many colleges and universities introduce art education into normal teaching process. Vocal music education is an important part of art education in colleges and universities (Baker \& Cohen, 2016; Raphael, 1991). Since vocal music education was introduced into college teaching, many experts and scholars have discussed how to more effectively integrate vocal music education into other teaching in order to achieve good results. However, in addition to the specialized art colleges, teaching methods of vocal music education have not yet formed a fixed pattern and its effect is barely satisfactory (Stegemöller, Skoe, Nicol, Warrier \& Kraus, 2008; Vallet, Loubaton, \& Mestre, 2016; Cevasco, 2008; Rykar, 2001).

What is thought-provoking is why vocal music education can be advanced well in art colleges but it is difficult to achieve the expected results in other colleges and universities. For this problem, part of studies hold that vocal music training is different from musical edification and need to have a certain basis of music theory and pronunciation (Webb, 2007; Bourret, Vollmer, \& Rapp, 2013). The lack of necessary knowledge reserves doesn't stimulate interest and even makes it more difficult to achieve results (Bele, 2005). On the basis of this cognition, this study introduces pronunciation training as the necessary basis of vocal music education into college teaching, probes into the change of teaching effect after the introduction of pronunciation training, and provides suggestions for the further reform of vocal music teaching in colleges and universities.

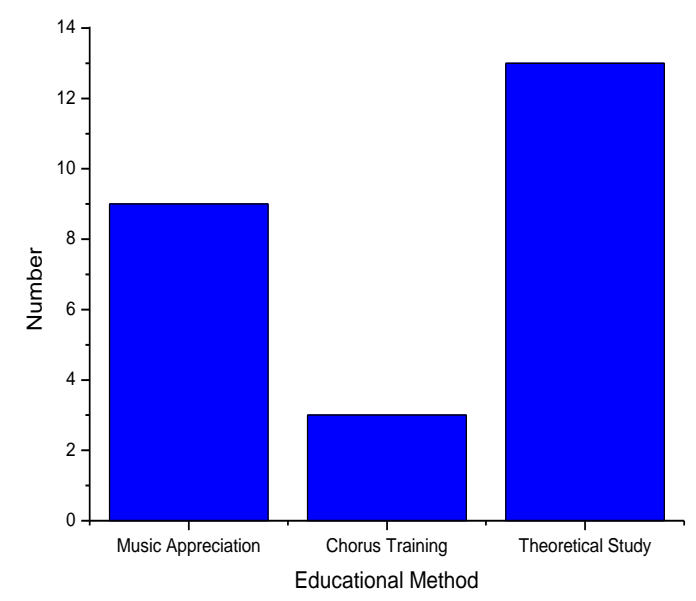

Figure 1. Educational Method of Vocal Training

\section{Status quo of vocal music education in colleges and universities}

Firstly, this study investigates the practical problems in the vocal music training in colleges and universities in China in order to put forward some suggestions on the improvement direction of vocal music education in colleges and universities. For convenience, the study mainly selects 25 colleges and universities in Shanghai and Beijing to carry out the vocal music education investigation, and all the selected colleges and universities 
have set up the vocal music education curriculum. The survey is conducted in the form of questionnaire. 150 questionnaires are sent out to each university. 3,750 questionnaires are sent out and 3,217 are collected, and the effective questionnaire rate is $85.79 \%$. Figure 1 and Figure 2 show the statistics of the satisfaction with vocal music education mode and vocal music teaching effect in colleges and universities respectively.

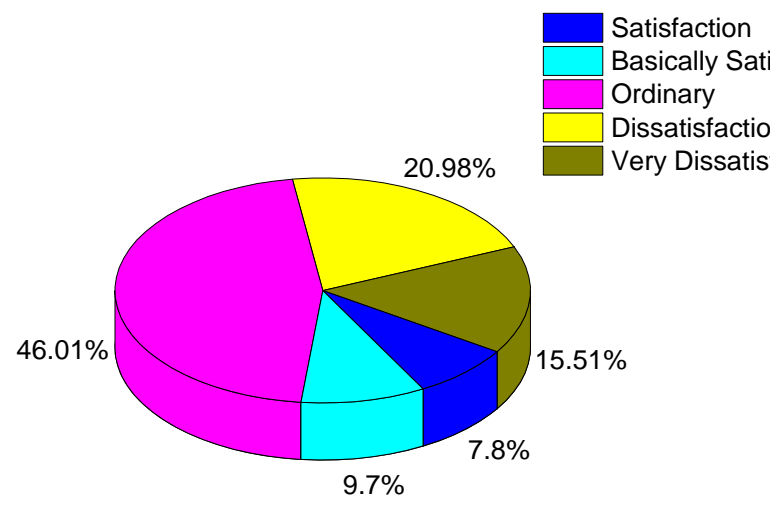

Figure 2. Overall Evaluation

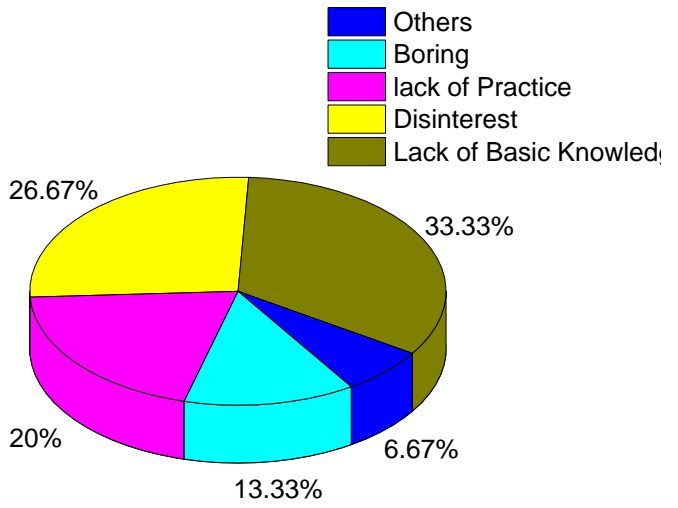

Figure 3. Cause Analysis of Dissatisfaction

It can be found that the ways of vocal music education in China can be divided into three categories: music appreciation, chorus training and theory learning. There are 9 colleges and universities adopting music appreciation teaching, 3 colleges adopting chorus training teaching, and 13 colleges adopting vocal music theory learning teaching. It is found that the most important vocal music teaching method in colleges and universities is pure theory teaching. However, the music theory of colleges and universities in China focuses on the history of music development and the differences between different music schools instead of teaching specific pronunciation or vocal music practice to students. According to the satisfaction degree of vocal music education, among 3,217 questionnaires, 251 (7.8\%) are satisfied, $312(9.7 \%)$ are basically satisfied, 1,480 (46.01\%) are 
general, 675 (20.98\%) are dissatisfied, and $499(15.51 \%)$ are very dissatisfied. The results show that only $17.50 \%$ of the results are satisfied or basically satisfied, and the ratio is very low. The following figure shows the reasons for the dissatisfaction of vocal music teaching according to the questionnaires. The proportion distribution is lack of basic knowledge (33.33\%), uninteresting teaching content (13.33\%), lack of practice opportunity (20\%), no interest $(26.67 \%)$ and others $(6.67 \%)$.

\section{Introduction and effect of pronunciation training}

From the above investigation, it is not difficult to find that the status quo of vocal music education in colleges and universities in China is not satisfactory, and the main reason is that students in non-art colleges lack necessary basic knowledge and practical opportunities. Therefore, it is very urgent to introduce pronunciation training into vocal music education in colleges and universities. This part mainly uses experiment to introduce the pronunciation training into the vocal music teaching in colleges and universities, and evaluates its actual effect.

\section{Pronunciation training mode}

Students from 25 colleges and universities mentioned above are taken as the research object and professional music teachers are invited to carry out the pronunciation training to them. According to the general music theory, the pronunciation training be carried out as follows (Broaduslawrence, Treole, Mccabe, Allen \& Toppin, 2000; Van et al., 2010): (1) The purpose of music score learning is to enable students to have the basic ability to recognize music score, and to have the ability to separate different syllables; (2) Tone learning and music score training are the basis of pronunciation training, and the purpose of tone training is to teach students to recognize the high and low tones of different syllables; (3) Pronunciation mode learning, on the basis of the recognition of music score and tone, students are trained to correct pronunciation mode, including oral type, breath, pronunciation part practice and so on; (4) Piece of music training, after a systematic learning of music score, tone and pronunciation mode, students are required to apply what they have learned to a whole piece of music. Each step needs to be carried out in sequence and us linked to each other. Professional teachers will guide and evaluate the training results after the end of the training so as to achieve better results. The following figure shows the basic steps of pronunciation training in 10 colleges and universities in this study.

\section{Pronunciation training effect}

We conduct pronunciation training for the subjects for one semester, and count the qualified level of each college's pronunciation training every month as the judgment standard of students' basic knowledge of music theory. Among them, whether their pronunciation is qualified or not is judged by professional teachers. The following table shows the changing trend of the qualified rate of pronunciation training. It is not difficult to find that the qualified rate of pronunciation level of all students after a semester of training has been increased to more than $60 \%$. In addition, the improvement of pronunciation level is often slow in the early training period and fast the later training period. 


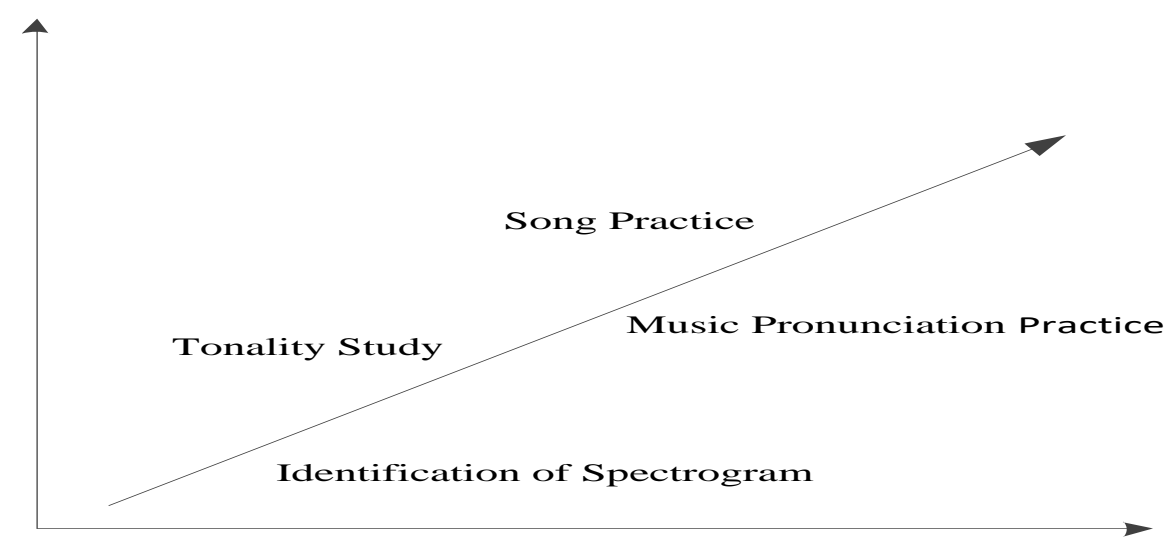

Figure 4. Steps of pronunciation training

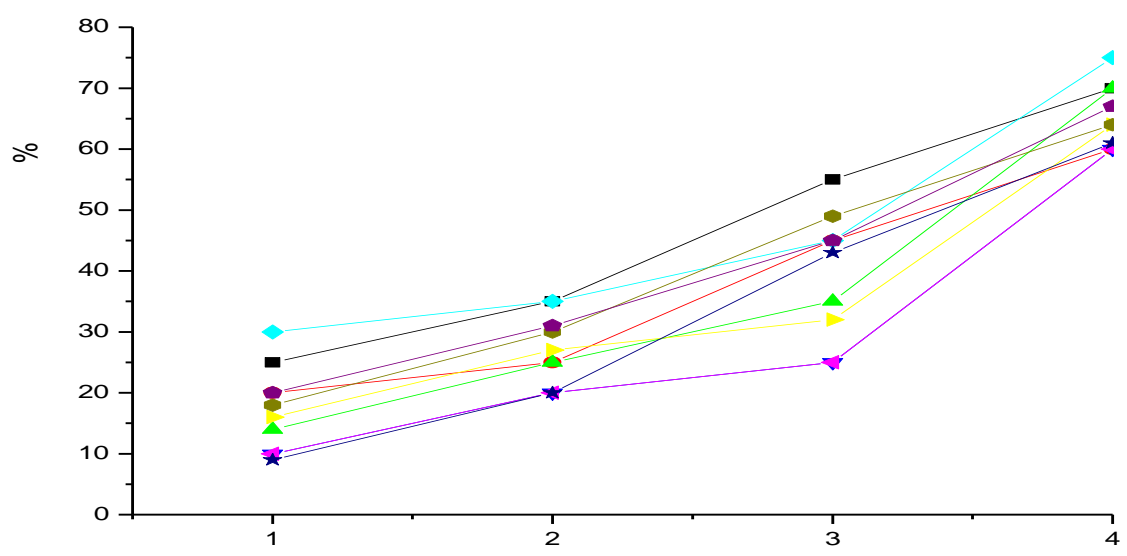

Figure 5. Qualified Rate of Pronunciation Training

\section{Promoting effect of pronunciation training on vocal music teaching}

After a semester of pronunciation training, we continue to track the vocal education and its effects in the next semester. This study evaluates the actual effect of pronunciation training at two levels. The first level is the actual score of the students who study vocal music in vocal music teaching, which is a hard index to measure the quality of vocal music teaching. The second level is to measure students' satisfaction with vocal music teaching, which is the soft index of vocal music teaching.

Figure 6 first shows the distribution of vocal music teaching scores before and after receiving pronunciation training for the tracked students. It is not difficult to find that before the pronunciation training, the students' scores are mainly distributed in the interval of 40 points, that is, the scores obtained by most students in vocal 
music study are extremely unsatisfactory. The reasons for this can be clearly seen in the investigation that students in the absence of basic music knowledge can't be stimulated the interest in learning of vocal music, and they naturally can't achieve ideal scores. After receiving the pronunciation training, the students have mastered the basic music knowledge and their vocal music scores have made the rapid progress, mainly concentrating in the interval of 70 scores, which is very rare and valuable a in the non-art colleges and universities.

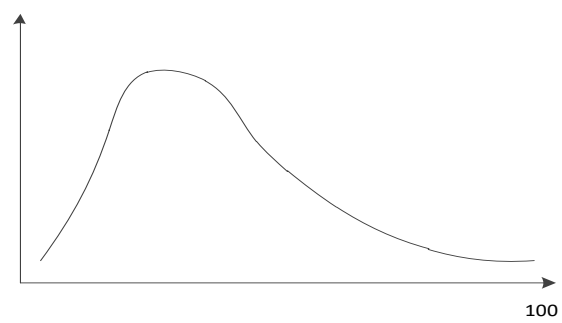

Before Training

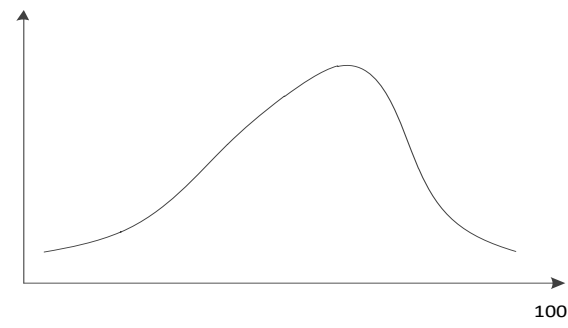

After Training

Figure 6. Score Distribution before/after Training

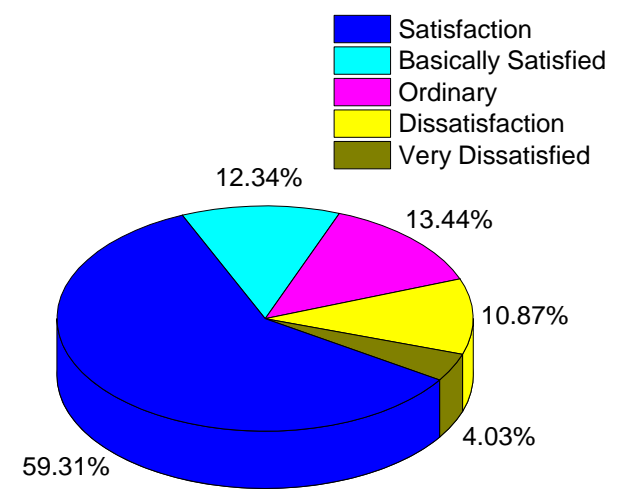

Figure 7. Overall Evaluation after Training

Figure 7 shows students' satisfaction with vocal music education after pronunciation training. The data show that the proportion of students satisfied with vocal music teaching increases significantly from $7.8 \%$ to $59.31 \%$ compared with the state before the pronunciation training. The proportion of students who are basically satisfied with vocal music teaching increases from $9.7 \%$ to $12.34 \%$, while the proportion of students who think vocal music teaching is general decreases from $46.01 \%$ to $13.44 \%$. The proportion of students who are dissatisfied with vocal music teaching drops from $20.98 \%$ to $10.87 \%$, while the proportion of students who are very dissatisfied with vocal music teaching decreases from $15.51 \%$ to $4.03 \%$. It can be seen that after the pronunciation training, the proportion of students who are satisfied with the vocal music teaching has increased significantly, while the proportion of students who are dissatisfied with the vocal music teaching has decreased significantly. 


\section{Conclusions}

Vocal music teaching is an important way to promote the all-round development of college students. Its teaching method is directly related to the achievement of teaching goals. Under the condition that the teaching effect of vocal music in colleges and universities is generally poor, this study introduces pronunciation training into vocal music teaching in colleges and universities, and tests the influence of pronunciation training on improving the teaching effect of vocal music through experiment. The main conclusions have been drawn as follows:

(1) At present, the teaching effect of vocal music in colleges and universities is generally poor and the root reason is that students from non-art colleges don't have the most basic knowledge of music theory and pronunciation, so it is difficult to form a reasonable understanding of vocal music teaching, making it difficult to raise interest in vocal music teaching.

(2) After a period of pronunciation training, students' basic music knowledge has been greatly improved, and the scores of vocal music teaching courses have been significantly increased, which shows that pronunciation training has a good effect on the teaching effect of vocal music.

(3) After the pronunciation training, students' vocal music teaching scores are improved. The main reason for the improvement is not only that the pronunciation training enables students to master the basic music knowledge, but also that students' cognition to the vocal music is improved after they master the basic music knowledge. In addition, teaching satisfaction and interest in learning have also increased.

\section{Reference}

Baker, V. D., \& Cohen, N. (2016). University vocal training and vocal health of music educators and music therapists. Update Applications of Research in Music Education, 35(3), 46-54. http://dx.dx.doi.org/ $10.1177 / 8755123316638517$

Bele, I. V. (2005). Artificially lengthened and constricted vocal tract in vocal training methods. Scandinavian Journal of Logopedics and Phoniatrics, 30(1), 34-40. http://dx.doi.org/10.1080/14015430510006677

Bourret, J., Vollmer, T. R., \& Rapp, J. T. (2013). Evaluation of a vocal mand assessment and vocal mand training procedures. Journal of Applied Behavior Analysis, 37(2), 129-144. http://dx.doi.org/10.1901/jaba.2004.37-129

Broadduslawrence, P. L., Treole, K., Mccabe, R. B., Allen, R. L., \& Toppin, L. (2000). The effects of preventive vocal hygiene education on the vocal hygiene habits and perceptual vocal characteristics of training singers. Journal of Voice, 14(1), 58-71. http://dx.doi.org/10.1016/s0892-1997(00)80095-8

Cevasco, A. M. (2008). Preferred vocal range of young and older adults: implications for music therapy majors' clinical training experience. Music Therapy Perspectives, 26(1), 4-12. http://dx.doi.org/10.1093/mtp/26.1.4

Raphael, B. N. (1991). The sounds of violence: Vocal training in stage combat. Theatre Topics, 1(1), 73-86. http://dx.doi.org/10.1353/tt.2010.0003 
Zhang, Xing / Study on the Application of Pronunciation Training in Vocal Music Teaching in Colleges and Universities

Rykar, K. S. (2001). Peer-reviewed article to train and test the voice in violence. Voice \& Speech Review, 2(1), 66-73. http://dx.doi.org/10.1080/23268263.2001.10761447

Stegemöller, E. L., Skoe, E., Nicol, T., Warrier, C., \& Kraus, N. (2008). Music training and vocal production of speech and song. Music Perception: An Interdisciplinary Journal, 25(5), 419-428. http://dx.doi.org/10.1525/mp.2008.25.5.419

Van Lierde, K. M., D'Haeseleer, E., Wuyts, F. L., De, L. S., Geldof, R., \& De, V. J. (2010). The objective vocal quality, vocal risk factors, vocal complaints, and corporal pain in Dutch female students training to be speech-language pathologists during the 4 years of study. Journal of Voice, 24(5), 592-598. http://dx.doi.org/10.1016/j.jvoice.2008.12.011

Vallet, P., Loubaton, P., \& Mestre, X. (2016). An improved music method for large sensor arrays, Traitement du Signal, 33(2-3), 223-248. http://dx.doi.org/10.3166/TS.33.249-272

Webb, J. L. (2007). Promoting vocal health in the choral rehearsal. Music Educators Journal, 93(5), 26-31. http://dx.doi.org/10.1177/002743210709300513 